\title{
Jane Austen and the Belly of the Beast Part 2 - Language and Power: Commodification, Technology and the Open Agenda in Higher Education
}

\author{
John Casey ${ }^{1, *}$, Wolfgang Greller ${ }^{2}$ \\ ${ }^{1}$ City of Glasgow College 60 North Hanover Street Glasgow G1 2BP, United Kingdom \\ ${ }^{2}$ Vienna University of Education Grenzackerstrasse 18, A-1100 Vienna, Austria \\ E-Mails: 1 john.c.casey@gmail.com; 2 wgreller@gmail.com
}

*Author to whom correspondence should be addressed; Tel.: +44(0) 7982322404

Panel: ICT\&S19 Critical/Radical Internet Studies, the University and Academia Today Accepted:

\section{Introduction}

This short paper discusses aspects of the interplay between ideology, technology, power and economics in the field of Higher Education, in the context of the crisis in neoliberalism. It continues a discussion begun in 2014 at the annual teaching and learning conference of Goldsmiths University, London. The title of the paper conveys the tensions between the perceived concepts and cultural forms of the university and the powerful forces changing our society - the tensions between manners and economics that underlie much of Jane Austen's work. The 'Belly of the Beast' is a colloquialism describing incarceration in prison or, more generally, to be trapped in a bad situation with few positive options, it provides a suitable metaphor for the dilemmas facing academics in the neoliberal university described by Hall (1).

The current scale of development in open education is both massive and diverse, making analysis difficult, as the authors of a recent study conclude in 'Open education: A study in disruption' [2]. Our approach is to begin to map some of the major landmarks and features in this space. This paper is part of a series of 'working sketches', with the aim of identifying the forces and powers at work below the surface of higher educational establishments. We see this mapping activity as providing a useful foundation upon which to develop alternatives, inside and outside the university, that can overcome 
existing problems and limits to teaching and researching about the Internet from a critical and radical perspective.

We begin by describing the background to our work and identify some important forces and ideas affecting universities and then continue with two of our working sketches, concluding with a summary. The two sketches presented in this paper are:

\section{1 - The Uses of Language}

How language, ideas and the use of (new) media both form and limit discourse to produce a 'monoculture', in relation to technology and education in particular and, more generally, the open education agenda.

\section{2 - Who Runs This Place?}

An overview and infographic representation that identifies the power structures at work and begins to map the political and economic interests in this space.

\section{Background}

The university sector has provided much of the 'intellectual soundtrack' for neoliberalism (as well as some principled opposition) and until relatively recently, the social capital of its inhabitants had been sufficient to avoid its worst effects. But, in the last 15 years or so the pressure from the neoliberal agenda has greatly intensified, through instrumentalist views of education, alignment with economic policy targets and calls for greater efficiency. The response to these pressures has been the 'massification' of higher of education, at first through simply building larger lecture theatres, more recently with technology. The problem at the heart of this situation is that the traditional university model of education is based on an economic and educational philosophy of scarcity, which has remained unchanged. The result is a university system that has been 'bulked up' like a bodybuilder on steroids that is hugely expensive to run, using poor educational methods to produce graduates who have fewer career opportunities, lower incomes and enormous debts they will never repay - educated into a form of financial and industrial servitude [3].

In the academic workplace, there is a growing culture of managerialism and intensification of labour to service much larger numbers of students with less staff. It is accompanied by a myopic shortterm focus on budgets, producing intense stress in staff [4] and a strategic vacuum that is easily filled by techno-hype. This is part of a global trend where previously secure middle class workforces are forced into an increasingly precarious existence [5]. As in other parts of the public sphere, this is accompanied by state-sponsored privatisation, as this extract from a UK government white paper makes clear:

“The government aims to 'drive competition and innovation', through a more market-based approach to higher education, allowing students to choose between a range of providers." [6] 
As the crisis deepens and spreads, austerity becomes a permanent economic and cultural control mechanism and in the process its political deliriums become less credible. In some ways this ideological breakdown can be seen most clearly in the university sector, until recently a central element of neoliberal economic development theory was the concept of the 'knowledge economy' and the key role of higher education was driving it forwards. This has shaped educational policy in the UK and around the world but its rationale is looking increasingly like a mystification as it is sharply contradicted by reality. The globalised economy is a low wage economy from which only a small minority can escape, as a UK educational research report concedes:

"highly rewarded, creative and autonomous work is likely to be restricted over the coming two decades to ever smaller global elites" [7]

This broad observation provides the backdrop and context to our work in the turbulent space where technology, ideology, education, power and economics meet.

\section{The Uses of Language}

Our approach in this section has been inspired by Hoggart's work on literacy and culture [8] and their relation to mass media, updated to include social media. In this connection, we examine how and why discourse in the area of education and technology appears to create a monoculture that is both 'apolitical' and aseptic. We identify a consistent element in this as being the language of fear, an essential function of the media under neoliberalism [5], especially the fear of being left behind others. This, together with intense commercial pressures, goes some way to explain the highly self-norming nature of debate within the educational technology community, acting as a powerful apparatus of control [9]. A recent example of this narrative of fear is "An Avalanche is Coming", published by a think tank [10], designed to manage the policy debate in favourable directions for commercial interests. The reference language of university management now closely aligns to commercial entities; managers, customers, marketing, product, innovation, ROI, etc. The "product" being the graduate envisaged by and designed for society as a useful asset to the labour market - a market that is rapidly shrinking.

This narrative is supported by a recurring stereotype of young people being more digitally literate and capable than they are in reality (so-called 'digital natives'), demanding more digital delivery of education, although research consistently refutes this distortion $[11,12,13]$. The role of 'celebrity experts' (often connected with universities) in constructing and projecting these narratives is an important one, the work of Mark Prensky [14] being notable. A recent example of the genre is Sebastian Thrun:

"Higher education in 50 years will be provided by no more than 10 institutions worldwide" [15]

The UK government Minister of State for Universities and Science duly regurgitated this line afterwards at a public meeting with University leaders [16]. We will examine the role of the celebrity expert and the use of traditional and social media in section two of this paper Who Runs This Place? 


\section{Who Runs This Place?}

In this section, we take our lead from the work of Anthony Sampson [17] who recorded and charted the changes to the structures of the UK establishment over a 40-year period reflecting the impact of globalisation. An innovation by Sampson that we will reuse is to create an info-graphical representation that represents how the different players are connected to each other and the size of their relative influence.

Corporate interests have long seen education as a huge global prize for privatisation, this was signalled by the inclusion of the trade in higher education services in the WTO GATT agreements [18] that laid the foundations for the current marketisation of the sector. One of the vectors for corporate entry has been the promotion of the use of technologies, such as interoperability standards, to make education more 'efficient'. The IT corporation CISCO and others were heavily involved in promoting this concept (imported from the military and industry training sectors) during the 'dot-com' boom and accompanying e-learning bubble of the late 1990's. As the CEO of CISCO stated:

"The next big killer application for the Internet is going to be education. Education over the Internet is going to be so big it is going to make e-mail usage look like a rounding error" [19]

Things did not work out that time and many of the e-learning enterprises and initiatives failed shortly afterwards in the dot-com crash, including the UK government sponsored UK e-University that tried to implement the interoperable philosophy of 'learning objects' [20].

Now, those arguments are being reactivated, as Weller observes [21] there is a media campaign, again with celebrity experts promoting the concept of a crisis in public education using the catch phrase 'education is broken' and proposing that the fix is a technical one [22]. As Klein [23] describes, the language of crisis as well as the actuality, is often used in political campaigns for the privatisation of publicly owned goods and services.

This is the context in which we discuss the relationships between universities, celebrity experts, IT corporations, think tanks, NGOs and charities, etc. For instance, the Mozilla foundation charity is involved in open education initiatives and is heavily funded by Google - who stand to gain from access to this new crop of analytic and demographic data.

\section{Summary}

In this short paper we have begun to map the turbulent space where technology, ideology, education, power and economics meet, concentrating on the uses of language and the forms and relations of the powers involved. We contend that in order to develop alternatives to the existing systems of education and overcome their problems and limits we should know from where we are starting.

\section{References}


1. Hall, G. Pirate Radical Philosophy. Radical Philosophy, 173, May-June 2012.

2. van Mourik Broekman, P.; Hall, G; Byfield, T.; Hides, S; Worthington, S. Open education: $A$ study in disruption. Rowman \& Littlefield International: London, 2014.

3. Debt campaigners tear up student loans, Pippa Stephens, BBC News 22-10-14

4. Death in academia and the mis-measurement of science, Arran Frood, EuroScience, 2015.

5. Hardt, M.; Negri, A. Empire, Harvard University Press, 2001

6. UK Government, The 2011 Higher Education White Paper, 2013

7. Facer, K. Final Report of the Beyond Current Horizons Research Programme, Future Lab: London, 2009

8. Hoggart, R. The Uses of Literacy, Penguin: London, 1966.

9. Foucault, M. The Birth of Biopolitics: Lectures at the Collège de France, 1978-1979, Editor Senellart, M, Palgrave Macmillan,: New York, 2008.

10. Barber, M.; Donnelly, K.; Rizvi, S. An Avalanche is Coming, Institute for Public Policy Research: London, 2013.

11. Information Behaviour of the Researcher of the Future, UCL: London 2008.

12. Jones, C.; Shao, B. (2011). The net generation and digital natives: implications for higher education, Higher Education Academy: York, 2011.

13. Kandiko, C.; Mawer, M. Student Expectations and Perceptions of Higher Education. QAA: Gloucester, 2013.

14. Marc Prensky - Wikipedia entry http://en.wikipedia.org/wiki/Marc_Prensky, 2015.

15. The Stanford Education Experiment Could Change Higher Learning Forever. Sebastian Thrun Interview, Steven Leckart, Wired Magazine: 20/3/12

16. Remarks made by David Willets at, 'Open and online learning:, Universities UK (16/5/13) Woburn House Conference Centre, London, 2013

17. Sampson, A. WhoRuns This Place? John Murray: London, 2004

18. Knight, J. Trade in Higher Education Services: The Implications of GATS, The Observatory on Borderless Higher Education: London 2002.

19. Next, It's E-ducation, Thomas Friedman, New York Times: (17 November), p. A29, New York, 1999.

20. Hefce pulls the plug on UK e-university, Donald MacLeod, The Guardian: London march 2004.

21. Weller, M. The Battle for Open: How openness won and why it doesn't feel like victory, Ubiquity Press: London, 2014.

22. Morozov, E. To Save Everything, Click Here, Allen Lane, Penguin Books: London 2013.

23. Klein, N. The Shock Doctrine: The Rise of Disaster Capitalism, Allen Lane, Penguin Books: London, 2008.

(C) 2015 by the authors; licensee MDPI and ISIS. This abstract is distributed under the terms and conditions of the Creative Commons Attribution license. 